\title{
New in 2010: The Science Transfer Series
}

Rosemary S. A. Shinkai

Editor-in-Chief
$\mathrm{T}$ The Revista Odonto Ciência (Journal of Dental Science) has the pleasure to introduce to our readers the Science Transfer Series, a set of guest editorials aiming to cover different initiatives and strategies to bridge the gap between academia and clinical community or industry.

To open the Science Transfer Series Dr John P. Hatch and Dr. John D. Rugh, from the University of Texas Health Science Center at San Antonio, USA, present their ongoing project to translate the scientific evidences into effective use in the daily clinics. The authors have been running a large study on dental education with NIH funding to test an education model of evidence-based practice that can inspire further actions or can be replicated in other target populations. Their goal is to provide long term instrumentation for dental students and clinicians to have autonomy in self-learning and clinical decision without being overwhelmed by the profusion of biomedical information from scattered sources.

Besides the discussion on the impact of scientific and technological advances on dental and continuing education, this issue also brings a review on the necessity of education adjustments in face of the public health policies in Brazil. The article presents the challenges for dental faculty and the requirements of dental curriculum to meet the profile of professionals needed to integrate the workforce in Public Health and Community Dentistry.

Finally, editors, researchers and graduate students are invited to attend a continuing education activity specifically designed for the dissemination of scientific information during the VII Meeting of Editors and Authors of Dental Journals in Rio de Janeiro, May 27-28 2010. Dr Zbys Fedorowicz, Director of the Steering Group of the Cochrane Collaboration and member of our International Editorial Board will lecture on systematic reviews and metaanalysis.

The Revista Odonto Ciência (Journal of Dental Science) wishes a good year of work and achievements to you. 